\title{
Neonatal cardiac surgery in low resource settings: implications of birth weight
}

\author{
Chamith Mendis Gunasekara, ${ }^{1}$ Katie Moynihan, ${ }^{2}$ Abish Sudhakar, ${ }^{1}$ \\ Gopalraj Sumangala Sunil, ${ }^{1}$ Brijesh P Kotayil, ${ }^{1}$ Praveen Reddy Bayya, \\ Raman Krishna Kumar (i) ${ }^{1}$
}

- Additional material is published online only. To view please visit the journal online (http://dx.doi.org/10.1136/ archdischild-2020-319161)

${ }^{1}$ Department of Pediatric Cardiology, Amrita Institute of Medical Sciences and Research Centre, Cochin, Kerala, India ${ }^{2}$ Cardiology, Boston Children's Hospital, Boston, Massachusetts, USA

\section{Correspondence to}

Dr Raman Krishna Kumar, Department of Pediatric Cardiology, Amrita Institute of Medical Sciences and Research Centre, Cochin, Kerala, India; kumar_rk@yahoo.com

Received 12 March 2020 Revised 31 May 2020 Accepted 22 June 2020 Published Online First 27 July 2020

\section{Linked}

- http://dx.doi.org/10.1136/ archdischild-2020-320026

Check for updates

(C) Author(s) (or their employer(s)) 2020. No commercial re-use. See rights and permissions. Published by BMJ.

To cite: Gunasekara CM Moynihan K, Sudhakar A et al. Arch Dis Child 2020:105:1140-1145.
ABSTRACT
Objective We sought to evaluate the association between low birth weight (LBW) and outcomes following neonatal cardiac surgery in a low-income and middleincome country setting where LBW prevalence is high and its impact on surgical outcomes is undefined.

Design Single-centre retrospective cohort study. Setting Referral paediatric hospital in Southern India Patients All neonatal cardiac surgical cases between January 2011 and December 2018. LBW was defined as $<2.5 \mathrm{~kg}$.

Main outcome measures Patient demographics, corrective versus palliative surgery and postoperative outcomes were collected from the institutional database which undergoes regular audit as part of International Quality Improvement Collaborative for Congenital Heart Disease. In-hospital mortality was the primary outcome measure.

Results of 569 neonatal cardiac operations, 123 (21.6\%) had LBW (mean: $2.2 \pm 0.3 \mathrm{~kg}$ ); $18.7 \%<2 \mathrm{~kg}$ and $21.1 \%$ were preterm ( $<37$ weeks). Surgery type (corrective vs palliative) or non-cardiac anomalies were not associated with birth weight. Birth weight did not correlate with ICU length of stay (LOS) and mechanical ventilation but was lower in those with postoperative sepsis. Overall in-hospital mortality was 7.0\%; LBW neonates had higher mortality (OR 2.16, 95\% CI 1.09 to $4.29, p=0.025)$. Multivariable analyses revealed birth weight (OR per $100 \mathrm{~g}$ decrease in weight: $1.12 ; 95 \% \mathrm{Cl}$ 1.03 to 1.22 ), age at surgery (OR per day increase in age of $0.93 ; 95 \% \mathrm{Cl} 0.87$ to 0.99$)$ and palliative intervention (OR 4.46 (95\% Cl 1.91 to 10.44) as independent predictors of in-hospital mortality.

Conclusion LBW adversely impacts in-hospital mortality outcomes following neonatal cardiac surgery in a resource-limited setting without increase in ICU or hospital LOS.

\section{INTRODUCTION}

Globally, the overwhelming majority of children with congenital heart disease (CHD) are born in low-income and middle-income countries (LMICs) as over $80 \%$ of the world's population live in these regions with relatively high birth rates. ${ }^{12} \mathrm{CHD}$ is increasingly recognised as a significant contributor to infant mortality and morbidity in LMICs. Due to sharp declines in readily preventable causes of infant mortality such as diarrhoea and pneumonia, CHD now ranks among the top five causes death between the ages of 1 month and 1 year in many

\section{What is already known on this topic?}

Higher rates of low birth weight are common among neonates with congenital heart disease in high-income settings, frequently attributable to prematurity.

- Low birth weight is is associated with significantly greater mortality and morbidity after neonatal heart surgery in high-income regions.

- A growing number of centres in low-income and middle-income countries are now performing neonatal cardiac surgery.

\section{What this study adds?}

- Low birthweight prevalence in neonates with congenital heart disease in our setting is high; however, prematurity is not a common cause.

- Low birth weight is an independent risk factor for mortality following neonatal cardiac surgery in low-income and middle-income country settings.

- While postoperative sepsis is commoner among low birth weight neonates, the duration of mechanical ventilation, ICU and hospital stay is the same.

LMIC settings. ${ }^{3}$ As a result, a growing number of centres in LMICs are now performing paediatric cardiac surgery with impressive improvements in outcomes. ${ }^{45}$ However, the absolute burden of CHD in LMICs remains considerable and of the 1.35 million children born each year with CHD, 90\% do not have adequate access to diagnostics or care. ${ }^{6}$

Neonatal heart surgery is particularly complex, with outcomes critically dependent on skilled human resources and infrastructure for perioperative care. In addition to resource constraints, significant challenges in LMICs relate to patient condition and comorbidities including undernutrition and respiratory infection. ${ }^{5}$ Low birth weight (LBW) and prematurity pose significant additional technical and management challenges in neonates with CHD. ${ }^{7}$ The proportion of neonates with LBW is significantly higher in LMICs. In India, nearly a quarter of babies are born with low birth weight as against the global average of $14.6 \% .^{8}$ 
Data from high-income nations suggest that LBW adversely impacts outcomes after surgery for CHD. ${ }^{9}$ Given the frequency of LBW infants with CHD and differing aetiology in LMICs, examining the implications of LBW on neonatal cardiac-surgical outcomes is essential to inform management decisions as this represents a potentially modifiable risk factor mitigated by improved maternal nutrition. We sought to evaluate the impact of LBW on early outcomes after neonatal congenital heart surgery in a LMIC setting.

\section{METHODS}

We conducted a retrospective cohort study of the institutional cardiac surgical database at a single centre in Southern India. All neonatal cardiac surgical procedures undertaken between January 2011 and December 2018 were included. This centre is one of five centres that serves a population of approximately 34 million in the state of Kerala and neighbouring regions. A detailed description of the study setting, care organisation structure in the unit and International Quality Improvement Collaborative for Congenital Heart Disease (IQIC; https://iqic.chboston. org/) has been published previously and with more data in online supplementary data. ${ }^{4}$ 10-13 Since 2010, key preoperative, operative and postoperative variables have been collected in the IQIC database with annual audit to ensure accuracy. ${ }^{4}$ Additional information pertinent to the study was collected from hospital records.

Neonates were defined as 28 days or younger and low birth weight as less than or equal to $2.5 \mathrm{~kg} .{ }^{14} 15$ Prematurity was defined as birth at less than or equal to 37 weeks' gestation and was obtained from the referring or local hospital obstetric medical records. ${ }^{15}$ Since a dedicated Fetal Cardiology service was instituted in 2008, an increasing number of neonates are delivered at our institution following prenatal diagnosis of critical CHD and timing of delivery is based on obstetric indications with preference for near term whenever possible.

Demographic variables collected included age at surgery, gender, length, prematurity, epoch of surgery (early 2011-2014 vs 2015-1018), associated major non-cardiac congenital malformations, chromosomal anomalies and other medical illness. Operative variables included type of surgical intervention (corrective vs palliative), as well as duration of cardiopulmonary bypass and cross-clamp. We also included the surgical risk stratification based on preoperative Risk Adjusted Congenital Heart Surgery (RACHS)-1 score. ${ }^{16}$ Due to low numbers in high-risk categories, patients were grouped into RACHS 1-3 and RACHS 4-6. The primary outcome was in-hospital mortality. Secondary outcomes included duration of mechanical ventilation, ICU stay, incidence of surgical site infection and postoperative bacterial or fungal (as per standard definitions) ${ }^{17}$ and additional mortality at 1 month.

Prior permission to access the hospital database to analyse and publish this data was obtained from the Institutional Ethics Committee.

\section{Statistical analysis}

For categorical variables, we presented the number and percentage. For normally distributed continuous variables, we presented the mean and SD. For continuous variable with distribution that was not normal, we reported the median and IQR. Independent sample t-test was used to compare birth weight by dichotomous demographic and outcome variables. Pearson correlation was used to compare the birth weight with demographic and continuous outcome variables. In situations where the continuous variables were skewed, they were logtransformed to meet the normality. Chi-square test was used to compare the categorical variables by mortality outcome. Binary logistic regression (unconditional) analysis using birth weight as a continuous variable was used to estimate OR with $95 \%$ confidence limits. Covariates that were associated with the primary outcome with a $\mathrm{p}$ value $<0.2$ were included in the model. Statistical analyses were conducted using SPSS V.20.0 for Windows.

\section{RESULTS}

During the 8-year study period, there were 569 neonates who underwent cardiac operations of whom 123 (21.6\%) had LBW (figure 1). In the LBW cohort, mean birth weight was $2.2 \mathrm{~kg}$ (SD \pm 0.3 ) with $18.7 \%$ patients below $2 \mathrm{~kg}$ and $21.1 \%$ born prematurely. Table 1 displays the baseline characteristics and outcomes of the whole study cohort. The proportion of preterm babies was higher in the LBW group. Figure 2 shows the proportion of preterm neonates in each of the weight categories. Operations performed in both groups were similarly distributed except for ligation of the patent arterial duct which was more common in LBW group $(8.1 \%$ vs $1.3 \% ; \mathrm{p}<0.001)$. Details on individual operations are presented in figure 1 and compared between the epochs in online supplementary data.

Table 1 also displays the association of birth weight with baseline characteristics and outcome. Birth weights were similar in males and females, those undergoing corrective versus those undergoing palliative operations, RACHS-I category groups 1, 2 and 3 versus 4, 5 and 6; those with and without non-cardiac and chromosomal anomalies and other medical illnesses. The birth weight was lower in the earlier admission epoch (2011-2015). Cardiopulmonary bypass and cross-clamp times showed no correlation with birth weight. Birth weights were significantly lower in those babies who died and those who developed bloodstream sepsis and higher in those who developed surgical site infection. Birth weights in those who died at 1 month trended towards lower values $(p=0.052)$. There was no correlation between birth weight and duration of mechanical ventilation, ICU and hospital stay.

Overall in-hospital mortality following neonatal cardiac surgery was $7.0 \%$. Those with LBW had twice the in-hospital mortality rate (OR 2.16, 95\% CI 1.09 to $4.29, \mathrm{p}=0.025$ ) (table 2). When restricting the cohort to the latter epoch, no difference was observed in in-hospital mortality between the two categories (OR 2.4, 95\% CI 0.7 to $8.4, \mathrm{p}=0.237$ ).

Univariable analysis (table 2) revealed younger age, birth weight, associated non-cardiac abnormality and operations performed in the early epoch to be associated with in-hospital mortality. In addition, postoperative sepsis was also significantly associated with in-hospital mortality Factors independently associated with mortality identified by multivariable analysis included birth weight, younger age at operation and palliative operations (table 3). For every $100 \mathrm{~g}$ decline, the incremental OR for mortality was $1.12 \%$ (95\% CI 1.03 to 1.22 ). Including low birth weight $(<2.5 \mathrm{~kg})$ as a categorical variable in multivariate analyses for in-hospital mortality revealed a significant increase in mortality risk (OR 2.4, 95\% CI 1.2 to $5.1, \mathrm{p}=0.019$ ).

\section{DISCUSSION}

We present the first large study examining the implications of LBW on neonatal cardiac surgical outcomes in a LMIC. Notably, the prevalence of LBW in our population is high with over $20 \%$ of neonates born with critical CHD in this series having LBW. We demonstrate an important impact of LBW on in-hospital 


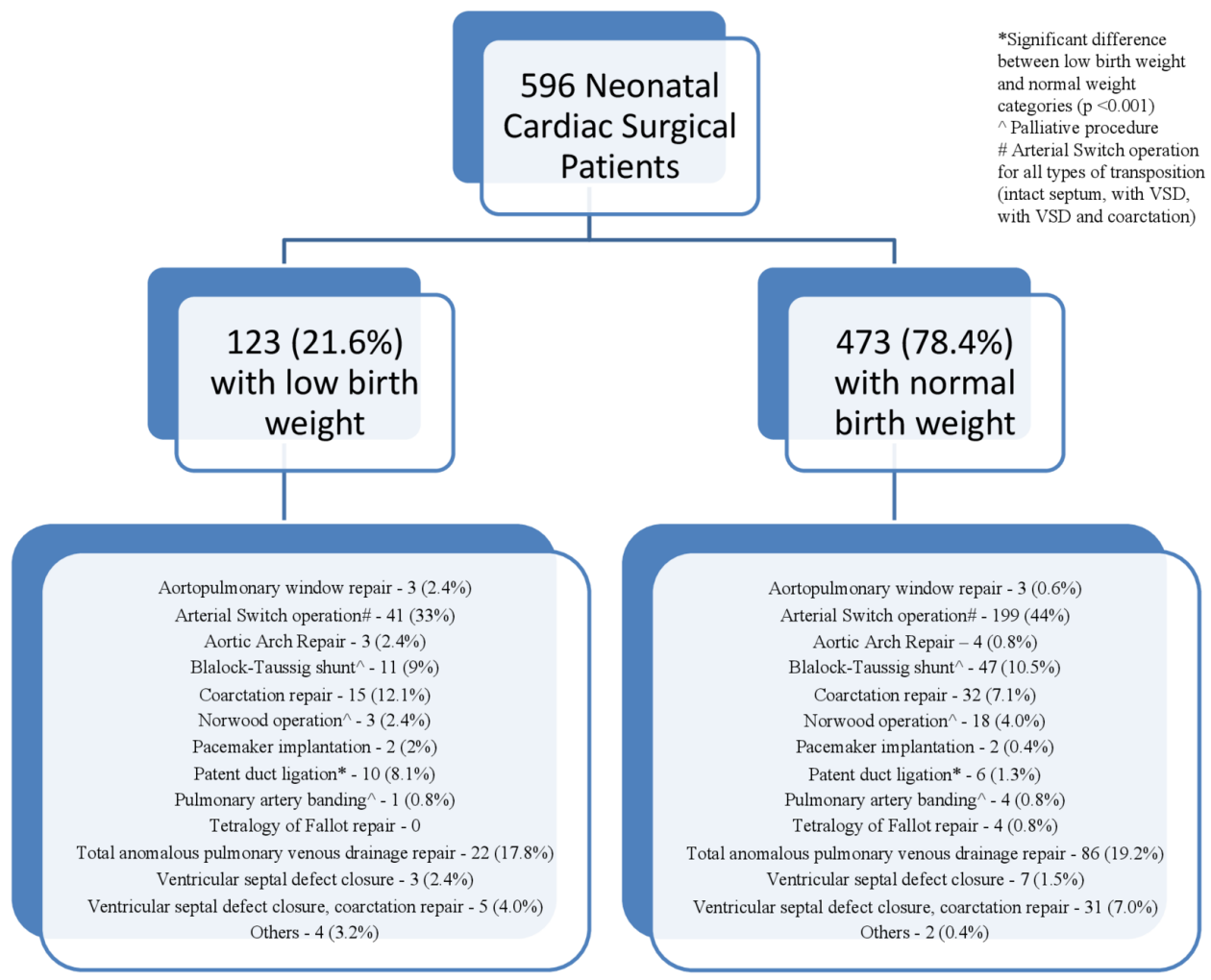

Figure 1 Consort diagram and distribution of heart operations in the low birthweight and normal birthweight categories. VSD, ventricular septal defect.

mortality outcomes following neonatal cardiac surgery in a low resource setting without an increase in ICU or hospital length of stay. Neonates with LBW had twice the in-hospital mortality rate of normal birthweight patients following neonatal cardiac surgery, and for every $100 \mathrm{~g}$ decrease in BW, mortality is increased by $12 \%$. LBW was an independent predictor of in-hospital death along with younger age at operation and palliative operations. Notably, for every day increase in postnatal age, a 7\% improvement in survival was observed. Prospective studies are required to further elucidate reasons for these findings which may represent modifiable risk factors for mortality in LMICs. Future directions will involve identifying interventions to increase birth weight, mitigate the impact of LBW on outcomes, and guide clinical decision-making and counselling of these vulnerable patients and their families.

The high proportion of neonates with LBW in our cohort exceeds global averages for LMIC. ${ }^{8} 18$ Previous studies from other parts of the world have also demonstrated higher rates of LBW among neonates with CHD. ${ }^{19}{ }^{20}$ In high-income nations, LBW predominately results from prematurity, with additional contribution from maternal illness, teen pregnancy, maternal substance abuse and smoking. ${ }^{21}$ In contrast in our cohort, only $20 \%$ of the babies with LBW were premature. This is consistent with the observation that in LMIC settings, the majority of LBW deliveries result from intrauterine growth retardation that is contributed significantly by maternal undernutrition. ${ }^{8} 18$ In this context, it is also recognised that the proportion of LBW infants reflects overall human development and quality of primary healthcare in the region. ${ }^{18}$ While the increasing importance of CHD as a cause of infant deaths in LMICs merits development of comprehensive paediatric cardiac care, ${ }^{3}$ low birth weight and undernutrition remain significant challenges that contribute to adverse outcomes. Our findings of increased LBW prevalence with important impact on patient outcomes suggest that improving the overall maternal health status should remain a priority. Focusing on public health initiatives as a means to increase birth weight may represent a modifiable risk factor to improve neonatal outcomes following CHD surgery. Nutritional counselling for mothers of prenatally diagnosed fetuses with CHD could address potential dietary shortcomings with research required to evaluate if this increases birth weight or impacts outcomes.

We observed LBW to be an important, independent risk factor for death after neonatal cardiac surgery in LMIC. Similar findings have been reported in high-income country settings. ${ }^{7}$ Potential reasons for increased mortality relate to reduction in overall reserves, increased vulnerability to postoperative sepsis and technical challenges associated with operating on very small babies. ${ }^{9}$ Notably, in our cohort, cardiopulmonary bypass and cross-clamp times were not associated with birth weight (table 1). There was a significant inverse association of postoperative sepsis with birth weight. This represents a potentially modifiable risk factor for poor outcomes. We have previously demonstrated the high incidence of postoperative sepsis from LMIC environments and also shown that it significantly contributes to postoperative mortality. ${ }^{17}$ Despite this, LBW had no impact on duration of mechanical ventilation, ICU or hospital stay in survivors. In contrast, data from developed nations describe LBW babies spending longer periods of time on the ventilator and in the ICU. ${ }^{9}$ Greater numbers of premature infants in high-income countries is a potential explanation as there is associated lung immaturity. In addition, it has also been shown that mortality and morbidity are lower for babies undergoing surgery at 39 weeks or later as compared with 37-38 weeks suggesting that maturation of the cardiorespiratory system continues beyond 37 weeks. $^{22}$ Investigation of the influence of surgical timing on 
Table 1 Patient characteristics and association of birth weight with demographic and outcome variables

\begin{tabular}{|c|c|c|c|}
\hline Variables tested & Overall cohort details $(n=569)$ & $\begin{array}{l}\text { Comparisons and correlations with } \\
\text { birth weight* }\end{array}$ & $P$ value \\
\hline Age (days) & $13.0 \pm 7.5$ & -0.159 & $<0.001$ \\
\hline \multicolumn{4}{|l|}{ Gender } \\
\hline Male & $355(62.5 \%)$ & $2.755 \pm 0.45$ & \multirow[t]{2}{*}{0.173} \\
\hline Female & $213(37.5 \%)$ & $2.817 \pm 0.52$ & \\
\hline Weight at surgery (kg) & $2.86 \pm 0.50$ & 0.903 & $<0.001$ \\
\hline \multicolumn{4}{|l|}{ Birthweight category } \\
\hline Normal & $445(78.3)$ & $2.987 \pm 0.37$ & \multirow[t]{2}{*}{$<0.001$} \\
\hline$<2.5 \mathrm{~kg}$ & $123(21.6 \%)$ & $2.170 \pm 0.30$ & \\
\hline Height $(\mathrm{cm})$ & $48.9 \pm 4.0$ & 0.417 & $<0.001$ \\
\hline \multicolumn{4}{|l|}{ Type of surgery } \\
\hline Corrective & $482(84.9 \%)$ & $2.797 \pm 0.50$ & \multirow[t]{2}{*}{0.773} \\
\hline Palliative & $86(15.1 \%)$ & $2.778 \pm 0.45$ & \\
\hline \multicolumn{4}{|l|}{ RACHS-I category } \\
\hline 1,2 and 3 & $334(58.8 \%)$ & $2.782 \pm 0.51$ & \multirow[t]{2}{*}{0.474} \\
\hline 4,5 and 6 & $232(40.8 \%)$ & $2.815 \pm 0.47$ & \\
\hline \multicolumn{4}{|l|}{ Prematurity } \\
\hline Absent & $541(95.2 \%)$ & $2.848 \pm 0.44$ & \\
\hline Present & $27(4.8 \%)$ & $1.852 \pm 0.45$ & $<0.001$ \\
\hline \multicolumn{4}{|l|}{ Non-cardiac abnormality } \\
\hline Present & $547(96.3)$ & $2.800 \pm 0.49$ & \multirow[t]{2}{*}{0.151} \\
\hline Absent & $21(3.7 \%)$ & $2.624 \pm 0.48$ & \\
\hline \multicolumn{4}{|l|}{ Chromosomal abnormality } \\
\hline Present & $558(98.2)$ & $2.797 \pm 0.49$ & \multirow[t]{2}{*}{0.346} \\
\hline Absent & $10(1.8 \%)$ & $2.640 \pm 0.49$ & \\
\hline \multicolumn{4}{|l|}{ Other medical illness } \\
\hline Present & $22(3.9 \%)$ & $2.799 \pm 0.49$ & \multirow[t]{2}{*}{0.234} \\
\hline Absent & $546(96.1 \%)$ & $2.665 \pm 0.56$ & \\
\hline \multicolumn{4}{|l|}{ Prenatal diagnosis } \\
\hline Absent & $486(85.6 \%)$ & $2.785 \pm 0.49$ & \multirow[t]{2}{*}{0.332} \\
\hline Present & $82(14.4 \%)$ & $2.846 \pm 0.50$ & \\
\hline \multicolumn{4}{|l|}{ Admission epoch } \\
\hline $2011-2014$ & $294(51.8 \%)$ & $2.746 \pm 0.46$ & \multirow[t]{2}{*}{0.026} \\
\hline 2015-2018 & $274(48.2 \%)$ & $2.844 \pm 0.52$ & \\
\hline Operations & & & \\
\hline Closed heart & $115(20.2 \%)$ & $2.677 \pm 0.59$ & 0.013 \\
\hline Open heart & $453(79.8 \%)$ & $2.828 \pm 0.46$ & \\
\hline Aortic cross-clamp time (min) & $113.0(76.0-141.3)$ & -0.032 & 0.556 \\
\hline Cardiopulmonary bypass time (min) & $189.0(145.8-237.3)$ & -0.022 & 0.671 \\
\hline Outcomes & & & \\
\hline In-hospital mortality & & & \\
\hline No & $529(93.1 \%)$ & $2.806 \pm 0.49$ & 0.021 \\
\hline Yes & $39(6.9 \%)$ & $2.589 \pm 0.47$ & \\
\hline Hospital stay (days) & $15.0(12.0-21.8)$ & 0.042 & 0.353 \\
\hline ICU stay (h) & & & \\
\hline All & $168.0(120.0-272.3)$ & -0.045 & 0.323 \\
\hline Survivors & $168.0(120.0-264.0)$ & & \\
\hline Decedents & $204.0(72.0-360.0)$ & & \\
\hline Ventilation duration (h) & & & \\
\hline All & $68.0(44.0-132.3)$ & -0.059 & 0.197 \\
\hline Survivors & $68.0(44.0-121.0)$ & & \\
\hline Decedents & $117.0(35.5-313.0)$ & & \\
\hline Surgical site infection & & & \\
\hline No & $523(92.1 \%)$ & $2.765 \pm 0.48$ & $<0.001$ \\
\hline Yes & $45(7.9 \%)$ & $3.136 \pm 0.53$ & \\
\hline Postoperative sepsis & & & \\
\hline
\end{tabular}


Table 1 Continued

\begin{tabular}{|c|c|c|c|}
\hline Variables tested & Overall cohort details $(n=569)$ & $\begin{array}{l}\text { Comparisons and correlations with } \\
\text { birth weight* }\end{array}$ & $P$ value \\
\hline No & $433(76.2 \%)$ & $2.824 \pm 0.48$ & 0.014 \\
\hline Yes & $135(23.8 \%)$ & $2.693 \pm 0.54$ & \\
\hline \multicolumn{4}{|c|}{ Additional 1-month follow-up mortality } \\
\hline No & $548(96.5 \%)$ & $2.802 \pm 0.49$ & 0.052 \\
\hline Yes & $20(3.5 \%)$ & $2.550 \pm 0.46$ & \\
\hline
\end{tabular}

*Correlation coefficient $(r)$ for continuous variables and mean $\pm S D$ for binary variables.

RACHS-I, Risk Adjustment for Congenital Heart Surgery.

early outcomes after operative repair for complex CHD in term neonates remains controversial. ${ }^{23} 24$ Although our data set was limited in to whether or not the baby was premature and not the exact gestational age, the inverse association between age and mortality observed in the multivariable analysis suggests that allowing a few days for postnatal 'maturation' may contribute to better outcomes. While numerous considerations dictate timing of neonatal heart surgery in LMIC, our findings support that delaying surgery may be another positive modifier of outcomes.

Overall mortality was $7 \%$, and this is higher than in developed centres from high-income nations, ${ }^{6}$ especially considering the fact that our study population includes a very small proportion of stage I palliations for hypoplastic left heart syndrome. Nonetheless, these results should not discourage efforts to providing cardiac surgery for neonates with LBW in LMICs especially given their relatively large prevalence. In the coming years, the number of neonates undergoing surgery from LMICs is likely to grow exponentially and these data can serve as a useful benchmark for those involved in care of neonates after cardiac surgery. Outcomes are likely to continue to improve in future years. Notably in the later epoch, fewer operations were performed on low birthweight infants, potentially attributable to institutional preference for catheter-based palliations (see online supplementary data). It will be interesting to see how much incremental mortality risk results from LBW in the coming years. When we examined the latter epoch of our database (2015-2018), we did not find a significant difference in mortality between LBW and normal birthweight neonates. Potential explanations include improved perioperative care that comes with experience in this cohort. Among the other independent contributors to mortality,

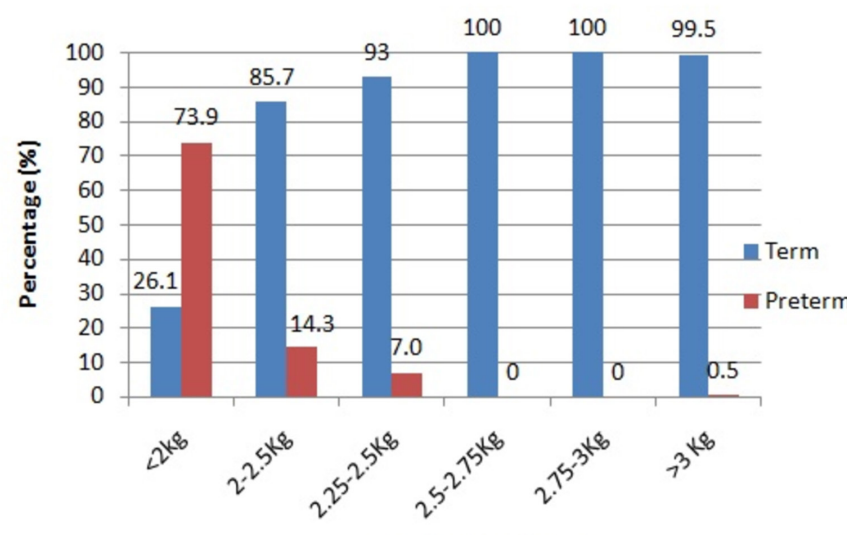

Birth weight group

Figure 2 Proportion of preterm neonates in the individual weight categories. The blue and orange bars represent percentages of term and preterm neonates, respectively. the most significant factors are palliative surgery and noncardiac abnormality. Both these factors are well recognised as non-modifiable risk factors for adverse outcomes after neonatal heart surgery. ${ }^{6} 11$

\section{Study limitations}

This was a single-centre study from a relatively well-developed part of India with an established infrastructure that may not be generalisable to LMIC populations as a whole. In addition, there are inherent limitations that result from the retrospective nature of the study. Specifically, information on the exact gestational age was unavailable among the term and preterm neonates; delineation of cause of death and maternal data (nutritional status, access to resources and education level) were not routinely collected. This information would make recommendations on maternal nutrition more relevant and potentially more specific. In addition, reasons for surgical timing in individual circumstances were not ascertained.

Table 2 Univariable analysis: association of preoperative risk factors with in-hospital mortality

\begin{tabular}{|c|c|c|c|}
\hline \multirow[b]{3}{*}{ Risk factors } & \multicolumn{2}{|c|}{ In-hospital mortality } & \multirow[b]{3}{*}{$P$ value } \\
\hline & No (529) & Yes (39) & \\
\hline & $\mathrm{n}(\%)$ & $\mathrm{n}(\%)$ & \\
\hline \multicolumn{4}{|l|}{ Gender } \\
\hline Male & $199(37.6)$ & $14(35.9)$ & \multirow[t]{2}{*}{0.83} \\
\hline Female & $330(62.4)$ & $25(64.1)$ & \\
\hline Age (days) mean \pm SD & $13.2 \pm 7.6$ & $10.3 \pm 5.6$ & 0.004 \\
\hline \multicolumn{4}{|l|}{ Weight group } \\
\hline Normal birth weight & $420(79.4)$ & $25(64.1)$ & \multirow[t]{2}{*}{0.025} \\
\hline Low birth weight & $109(20.6)$ & $14(35.9)$ & \\
\hline Birth weight (kg) & $2.81 \pm 0.49$ & $2.59 \pm 0.47$ & 0.021 \\
\hline \multicolumn{4}{|l|}{ Type of surgery } \\
\hline Corrective & $461(87.1)$ & $21(53.8)$ & \multirow[t]{2}{*}{$<0.001$} \\
\hline Palliative & $68(12.9)$ & $18(46.2)$ & \\
\hline Non-cardiac abnormality & $15(2.8)$ & $6(15.4)$ & $<0.001$ \\
\hline Chromosomal abnormality & $9(1.7)$ & $1(2.6)$ & 0.512 \\
\hline Other medical illness & $21(3.9)$ & $1(2.6)$ & 1 \\
\hline Surgical site infection & $43(8.1)$ & $2(5.1)$ & 0.759 \\
\hline Postoperative sepsis & $114(21.6)$ & $21(53.8)$ & $<0.001$ \\
\hline \multicolumn{4}{|l|}{ RACHS-I category } \\
\hline $1-3$ & $311(58.8)$ & $23(59)$ & \multirow[t]{2}{*}{0.996} \\
\hline $4-6$ & $216(41.2)$ & $16(41)$ & \\
\hline \multicolumn{4}{|l|}{ Admission epoch } \\
\hline 2011-2014 & $267(50.5)$ & $27(69.2)$ & \multirow[t]{2}{*}{0.024} \\
\hline 2015-2018 & $262(49.5)$ & $12(30.8)$ & \\
\hline
\end{tabular}


Table 3 Multivariable analysis: independent risk factors for inhospital mortality following neonatal cardiac surgery in a LMIC setting

\begin{tabular}{lll}
\hline Risk factors & OR $(95 \% \mathrm{Cl})$ & P value \\
\hline $100 \mathrm{~g}$ decrease in birth weight & $1.12(1.03$ to 1.22$)$ & 0.009 \\
\hline Palliative surgery & $4.46(1.91$ to 10.44$)$ & 0.001 \\
Day increase in age & $0.93(0.87$ to 0.99$)$ & 0.02 \\
\hline
\end{tabular}

Birth weight, surgery type, age, admission epoch and non-cardiac anomaly were considered for regression analysis.

\section{CONCLUSIONS}

The prevalence of LBW in our CHD population is high. We demonstrate an important impact of LBW on in-hospital mortality outcomes following neonatal cardiac surgery in a low resource setting without an increase in ICU or hospital LOS. While efforts to improve perioperative care and reducing postoperative infections should continue, it is also essential to consider interventions to improve maternal nutrition.

Acknowledgements $\mathrm{KJ}$ and the International Quality Improvement Collaborative for enabling the database at the institution. SB (Oregon State Health University, USA), KKD (MOSC Medical College, Kolenchery, Kerala, India) and RV (HN Reliance Hospital, Mumbai, India) for critically reviewing the manuscript.

Contributors CMG collected the data and wrote the initial draft of the manuscript $\mathrm{KM}$ helped plan the analysis and provided critical inputs throughout the manuscript preparation. AS performed the data analysis. GSS, BPK and PRB were the surgeons who operated on the neonates described in the study. They reviewed the manuscript and provided critical inputs. RKK is the senior and the corresponding author who conceptualised the study, planned the analysis and revised the draft.

Funding The authors have not declared a specific grant for this research from any funding agency in the public, commercial or not-for-profit sectors.

Competing interests None declared.

Patient consent for publication Not required.

Ethics approval Institutional Ethics Committee of the Amrita Institute of Medical Sciences; Approval ID No. IEC-AIMS-2020-CARD-014.

Provenance and peer review Not commissioned; externally peer reviewed.

Data availability statement Data are available on reasonable request. Deidentified data on all patients in this study is available with RKK (kumar_rk@yahoo. com) and these can be provided on formal request. RKK will seek approval from the Institutional Ethics committee before the data can be shared.

ORCID iD

Raman Krishna Kumar http://orcid.org/0000-0003-4343-0951

\section{REFERENCES}

1 A very unequal world. Available: http://www.livemint.com/Money/karpcZ5QqTzd065j vAROIL/A-very-unequal-world.html [Accessed 21 May 2020].

2 A case for the invisible child. Available: https://childrensheartlink.org/wp (content/ uploads/2017/06/The-Invisible-Child-Brief-1.pdf [Accessed 21 May 2020]
3 GBD 2017 Congenital Heart Disease Collaborators. Global, regional, and national burden of congenital heart disease, 1990-2017: a systematic analysis for the global burden of disease study 2017. Lancet Child Adolesc Health 2020;4:185-200.

4 Jenkins KJ, Castañeda AR, Cherian KM, et al. Reducing mortality and infections after congenital heart surgery in the developing world. Pediatrics 2014;134:e1422-30.

5 Reddy NS, Kappanayil M, Balachandran R, et al. Preoperative determinants of outcomes of infant heart surgery in a limited-resource setting. Semin Thorac Cardiovasc Surg 2015;27:331-8.

6 Zheleva B, Atwood JB. The invisible child: childhood heart disease in global health. Lancet 2017:389:16-18.

7 Kalfa D, Krishnamurthy G, Duchon J, et al. Outcomes of cardiac surgery in patients weighing <2.5 kg: affect of patient-dependent and -independent variables. J Thorac Cardiovasc Surg 2014;148:2499-506.

8 Blencowe $\mathrm{H}$, Krasevec J, de Onis M, et al. National, regional, and worldwide estimates of low birthweight in 2015, with trends from 2000: a systematic analysis. Lancet Glob Health 2019;7:e849-60.

9 Curzon CL, Milford-Beland S, Li JS, et al. Cardiac surgery in infants with low birth weight is associated with increased mortality: analysis of the Society of Thoracic Surgeons Congenital Heart Database. J Thorac Cardiovasc Surg 2008;135:546-51.

10 Balachandran R, Nair SG, Gopalraj SS, et al. Dedicated pediatric cardiac intensive care unit in a developing country: does it improve the outcome? Ann Pediatr Cardiol 2011;4:122-6

11 Balachandran R, Nair SG, Kumar RK. Establishing a pediatric cardiac intensive care unit—special considerations in a limited resources environment. Ann Pediatr Cardiol 2010;3:40-9.

12 Rao SG. Pediatric cardiac surgery in developing countries. Pediatr Cardiol 2007:28:144-8

13 Kumar RK, Tynan MJ. Catheter interventions for congenital heart disease in third world countries. Pediatr Cardiol 2005:26:241-9.

14 Cutland CL, Lackritz EM, Mallett-Moore T, et al. Low birth weight: case definition \& guidelines for data collection, analysis, and presentation of maternal immunization safety data. Vaccine 2017;35:6492-500.

15 World Health Organization. Infant, newborn, 2020. Available: https://www.who.int/ infant-newborn/en/ [Accessed 21 May 2020].

16 Jenkins KJ. Risk adjustment for congenital heart surgery: the RACHS-1 method. Semin Thorac Cardiovasc Surg Pediatr Card Surg Annu 2004;7:180-4.

17 Sen AC, Morrow DF, Balachandran R, et al. Postoperative infection in developing world congenital heart surgery programs: data from the International Quality Improvement Collaborative. Circ Cardiovasc Qual Outcomes 2017;10:e002935.

18 India State-Level Disease Burden Initiative Malnutrition Collaborators. The burden of child and maternal malnutrition and trends in its indicators in the states of India: the global burden of disease study 1990-2017. Lancet Child Adolesc Health 2019;3:855-70.

19 Kramer HH, Trampisch HJ, Rammos S, et al. Birth weight of children with congenital heart disease. Eur J Pediatr 1990;149:752-7.

20 Petrossian RA, Kuehl KS, Loffredo CA. Relationship of birth weight with congenital cardiovascular malformations in a population-based study. Cardiol Young 2015:25:1086-92.

21 Low birthweight. Available: https://www.americashealthrankings.org/explore/annual/ measure/birthweight/state/ALL [Accessed 21 May 2020].

22 Costello JM, Pasquali SK, Jacobs JP, et al. Gestational age at birth and outcomes afte neonatal cardiac surgery: an analysis of the Society of Thoracic Surgeons Congenital Heart Surgery Database. Circulation 2014;129:2511-7.

23 Karamlou T. Optimal timing for arterial switch in neonates with transposition of the great arteries: an elusive target. J Am Coll Cardiol 2014:63:488-9.

24 Anderson BR, Ciarleglio AJ, Hayes DA, et al. Earlier arterial switch operation improves outcomes and reduces costs for neonates with transposition of the great arteries. J Am Coll Cardiol 2014:63:481-7. 